\title{
COM \\ Steak and bleach as science communication heroes? The rise of post-corona, posthuman irony
}

\section{Pádraig Murphy}

Abstract

Keywords

DOI

Introduction
Since early 2020, communicating risks associated with COVID-19 and providing safety advice have been top priorities for health agencies and governments. With an increase in employees working remotely following the global spread of coronavirus coupled with increasingly sophisticated marketing strategies, global brands unsurprisingly engaged consumers and publics by acknowledging the crisis that engulfed the world. An increase in online marketing was observed in an already existing trend online where hybrids of consumer, brand and product-as-object interacted as equals, using contemporary informal codes of social media discourse and often using irony and humour.

However, this paper critically assesses how such important communication responsibilities about coronavirus were taken up by private companies. Online and social media outputs were analysed through a lens of anthropomorphising and posthuman brands. A typology of brand strategies was developed based on engagement and how COVID-19 science, care and prevention were communicated. The paper concludes with a reflection on where this may lead health and environmental communication and what it means for science communicators.

Health communication; Public engagement with science and technology; Risk communication

https://doi.org/10.22323/2.20050203

Submitted: 12th September 2020

Accepted: 7th June 2021

Published: 30th August 2021

With the emergence of COVID-19 across the world in 2020, a significant physical withdrawal occurred as businesses and schools halted face-to-face activities and, for many people, work and education were conducted online. There was an increased dependency on online methods of connection for communities and various practices, whether work, leisure or just the human need to stay in touch. Online methods of health communication also increased [Budd et al., 2020]. With an increased number of employees working remotely following the global spread of coronavirus and an increasing sophistication in marketing strategies, global 
brands unsurprisingly engaged consumers and publics by referencing the crisis that engulfed the world. During the COVID-19 crisis, publics appeared to need familiar brands to maintain a link with some kind of normality during various lockdowns and transport them away from the restrictive measures while at the same time acknowledging the trauma of their predicament [Edelman, 2020]. Market research company Kantar [2020] reported that people were growing weary of reminder messages in adverts during the pandemic. Home entertainment was also a clear priority.

Throughout the pandemic, the speed at which science operated within the uncertainties of COVID-19 aligned with the increased need for public information and this inevitably led to an increase in errors, misunderstandings and ambiguous knowledge. Rumour, conjecture and debate were mixed with strategic attempts by governments and health agencies at simple messaging. Concerns were raised at the beginning of the crisis about what the WHO and UN had labelled an "infodemic" of false information [Department of Global Communications, 2020; WHO, 2021]. Social media was seen as the main misinformation threat [Ofcom, 2020]. However, humour and irony were, as always, important communication tools in this serious crisis to increase engagement [Joubert and Wasserman, 2020; Riesch, 2015]. It is how humans respond to important events and its use can blur the boundaries of taste, affect and accuracy. The point of satire is to attack injustice while including the marginalised.

Humour, satire and irony also become part of how media ecosystems facilitate the emergence of hybrids using informalised practices of identity-building online [Chadwick, 2017; Couldry and Hepp, 2017; Kuipers, 2016]. In this instance, expertise, fact and opinion were entangled more than usual as corporations, hobby forums and interest groups connected with each other using the emerging social media of TikTok, Instagram and Twitter. A light-touch humanity was now made visible, something other-than-human yet with recognisable human characteristics online and offline - products as objects rooted in a material world yet represented online and brands reconceptualised and anthropomorphised as forms of celebrity. The crucial new configuration here is the humanisation and moralisation of brands using irony and humour, a reflexive knowingness of brands as objects, yet also anthropomorphised (and as we see later a movement from anthropomorphism towards posthumanism).

In parallel with this progression of online hybridity, a leadership vacuum appeared in political responses to COVID-19 and strategic health communications in many parts of the world during the pandemic [Applebaum, 2020; Newell, 2020]. While there were calls from many countries for a spirit of solidarity, commercial entities appeared to step in to do the urgent work of communicating science where this was lacking. As political leaders appeared to flounder, these health and political leadership vacuums become partially filled by private interests and automated services sometimes manifested within these online spaces of identity play. It was possible for the companies replacing this scientific and policy mediation to protect themselves from criticism by declaring ironic intentions knowing that consumers were aware that they are still, above all else, just selling a product. Any increase in informative health science that has commercial interests at its source raises questions of authority and impartiality. There are clear implications here - and lessons to be learned - for science communicators within this changing landscape. 
There are three converging contexts of branding during the pandemic that warrant consideration:

1. A tendency towards increased public stakeholder input in brand identification and a reciprocated type of ethical marking or branding supposedly containing a social conscience as part of corporate social responsibility (CSR) [Dubbink and van Liedekerke, 2020; Jahdi and Acikdilli, 2009], called here the moralising of capital;

2. Trends in product marketing toward ironic advertising [Logan, 2016; Warren and Mohr, 2017] and the role of satirical humour;

3. A posthuman turn in both the sociality of digital communication and of marketing [Campbell, O'Driscoll and Saren, 2010; Campbell, Deane and Murphy, 2015; Couldry and Hepp, 2017; Kalpokas, 2019; Kozinets, 2008; Kozinets, 2015; Thrift, 2004; Thrift, 2005; Thrift, 2014].

In these converging, somewhat contradictory contexts, a challenging type of science communication emerges where private companies become 'informal informants' for COVID-19 as part of a new social media discourse combining elements of the critical science-policy interface [Colglazier, 2020]. While humour, satire and irony can be difficult to use for strategic communication - and they evade easy analysis - there is evidence that they also have their place as tools for science communication [Becker and Anderson, 2019; Brewer and McKnight, 2015; Joubert and Wasserman, 2020; Riesch, 2015].

With the spread of coronavirus however and the urgent crisis communication needed for pandemic information, it is pertinent to ask: what role, if any, do corporations have in communicating the science of COVID-19 and its prevention even if it is by the mechanism of ironic forms CSR? Who has most responsibility for communicating health science during an extreme global disruption event such as a pandemic when online identities and facts themselves have become increasingly more fluid? Given the anti-capitalist humour and nuance of certain marketing campaigns, is there a subversion taking place?

These are the broad questions addressed by this paper focusing centrally on ironic posthuman identities as defenders of science and the implications this has for communicating health science. The specific objectives of the paper are:

- to examine how online representations of brands create new spaces for scientific engagement on social media in the context of private organisations' use of ethical branding and informal discourses, using humour, celebritisation and irony;

- to track the posthuman interplay between products-as-objects and products-as-brands in online spaces where publics were informed about coronavirus and COVID-19;

- to explore how the coronavirus and COVID-19 are communicated by brands and categorise the brands' use of communication, and further explore the implications when companies are among the most visible science communicators during a health crisis. 
I will begin by setting out the context of how popular anthropomorphic play online is mixed with celebritisation and how brands flood these spaces. This, I argue, is central to how we understand the broader changes occurring - humanised products at play that reflect a trend towards greater posthumanism online. Examples are presented of the anthropomorphism of brands, shifting towards posthuman brands. The theoretical construct is then outlined, where I reflect on how a posthumanist, networked, informational capitalism [Arvidsson, 2006; Arvidsson and Colleoni, 2012; Boltanski and Chiapello, 2005] has implications for pandemic science communication. A paradoxical ethic emerges in these outward projections of capitalist systems where hybrids of brand, product and consumer emerge with elements of posthuman characterisation, appearing as mythic and heroic. They are seen to have an almost-human or more-than-human persona which defends science and/or social equality.

I then go through the methodology before presenting two exemplar cases. There was a strange moment during the pandemic when the words "disinfectant", "bleach" and "Dettol" trended on Twitter and become central to U.S. political debate around combating coronavirus. Much lower key was the Twitter activity of Steak-umm, a U.S.-based frozen meat company, which became involved in science and media communication localised in the U.S. at a time where this was lacking from the political and health policy systems. The analytical section will set out a typology of communication strategies for brands on COVID-19, which I call here "faces" of a company or brand. This is a deeper analysis of 100 brands during COVID-19 ranging from those which tweaked their marketing to emphasise the policy message to "stay at home" to those companies that set out detailed scientific information about coronavirus to publics and/or potential customer. The faces described in this later section are public faces and in some cases multiple types are displayed as the company and/or the brand switches register to deal with COVID-19. This typology of faces becomes a useful way to track the health communication and degree of engagement used. The final section assesses what this means for the changing roles of science communication. What is new about these spaces is the convergence of moralising capital, posthuman marketing and urgent COVID-19 communication in one accelerated moment.

Context:

examples of the celebritisation of brands and anthropomorphising and moralising capital
In William Gibson's [1996] sci-fi novel Idoru set in a digital posthuman future, the rock star character Rez is a tabula rasa who projects outwards how others see him to the point of constant surgical altering of his appearance to allow himself to be a youthful reflection of public expectation. The self-described "netnographer" Robert Kozinets describes Rez as

a complete personal brand empire unto himself... an empty shell of a person, somehow completely hollowed out. He is like a shadow, an alien, a digital cloud of static. He is not traceable or even recognizable as an actual human being [Kozinets, 2015, p. 152].

Kozinets' framing of Rez tells us something about corporeal digital identities that heralds a future already here. He is a constructed corporate identity made flesh and while relational identity theories often focus on how identity is created from the contingency of the relation itself rather than the objects that are somehow 
related to each other [Michael, 1996], some theorists present reasonable evidence that materialist, embodied products are also necessary in this identify formation. From this perspective, contemporary identities are co-created by the reliance on objects of consumption and their ever-presence as cultural artefacts in contemporary lives [Campbell, O'Driscoll and Saren, 2010; MacInnis and Folkes, 2017; Thrift, 2004; Turner Schenk and Holman, 1980]. Rez, in this reading, would be the sum of his aesthetic surgery and the commodities surrounding his body and life. He can be viewed through a contemporary lens as a caricature or extreme version of an online consumer identity seeking materiality. With increased movement to online environments, a playful posthumanism has emerged which draws from this connected sociality [Thrift, 2014] seeking gratification not only in the digital world but privileging new types of interaction with things. We explore here how this could be further intensified by the COVID-19 pandemic and its connection with corporate science communication.

Let us first explore examples of brands demonstrating a moralising of capital as well as the related use of ironic marketing before looking at how these might be humanised and posthumanised. An example of ethical marketing is Starbucks' Race Together initiative challenging casual racism which started in the U.S. and was then implemented globally [Logan, 2016]. The Starbucks coffee chain store company has had several charges of racism brought against its U.S. outlets over the years [Nabi, 2018]. It was the decision of Starbucks CEO Howard Schulz to organise top-down staff training and some aspect of "dialogue" about racism between staff and publics [op. cit.]. The pushing of the issue at global corporate level increased its newsworthiness. However, the idea drew public and chat show hostility. A much darker episode in U.S. history of racial politics was the killing of George Floyd by white Minneapolis police officers in 2020. This event became a catalyst for mass global protests, with masked citizens resisting social distancing guidelines to take to the streets, which - more frivolously - gained support from the entertainment industries. The U.S.-based ice cream manufacturer Ben and Jerry's, under the ownership of Unilever, initiated a campaign against systemic racism including strong statements written on their products such as "inhumane police brutality... perpetuated by a culture of white supremacy".

There was a degree of public scepticism in each of these cases about the use of marketing tools or certain forms of entertainment as platforms to raise awareness about sensitive cultural issues or deep-rooted historical prejudices [Cobb, 2018; Kiefer, 2020]. The U.S.-based sugared drinks manufacturer SunnyD drew similar criticism in 2019 for allegedly referencing mental health in an inappropriate way with the simple tweet "I can't do this anymore". Similarly, Gillette, the U.S. shaving products brand owned by the U.S.-based Proctor and Gamble company, was criticised for what was described as light-touch sentimentality tied into commercialism when producing a 2019 advertising campaign challenging toxic masculinity [Abitbol, 2019]. While such companies receive praise, critics are quick to point out if a company has been involved in other types of social or environmental injustices in its production processes. In these cases, the institutional CSR approaches miss the mark. Social justice has long been a core value of traditional left politics. It sits uneasily as a theme for market strategy. Large-scale marketing, no matter how ethical the intentions, can miss the historical and contextualised intersectional issues of race, gender, sexuality, environment and class. Journalist Amanda Hess, writing in the New York Times, demonstrated how 
labour was ever visible from the cranes reaching to the sky to workers lifting pallets, or shelves being stacked during the pandemic. Workers were needed to keep production going at the factory or office, conveyor belts running to keep production going across the world, as well as health workers of course [Hess, 2020]. While such values are not usually associated with commercial branding, a specific type of social ethics in marketing attempts to do so [Dubbink and van Liedekerke, 2020], however tenuous.

One ethical approach might be to employ forms of ironic marketing [Warren and Mohr, 2017], where potential buyers are encouraged not to buy a product as part of either a segregation of markets or increasing the ethical capital of that brand. An example from the U.K. is Yorkshire Tea. This is a family-run business, over 200 years old, which positions itself as a grand British institution, selling a very British pastime - drinking tea. During the height of the \#BlackLivesMatter (BLM) protests, the company offered support in "solidaritea". One tweet, shown in Figure 1, demonstrates Yorkshire Team responding to a racist tweet that the sender may erroneously have felt could position the protests against the backdrop of certain nationalist and xenophobic conditions of Brexit. The Yorkshire Tea response can be viewed as a type of anti-marketing ironically placed within the heart of the capitalist paradigm.

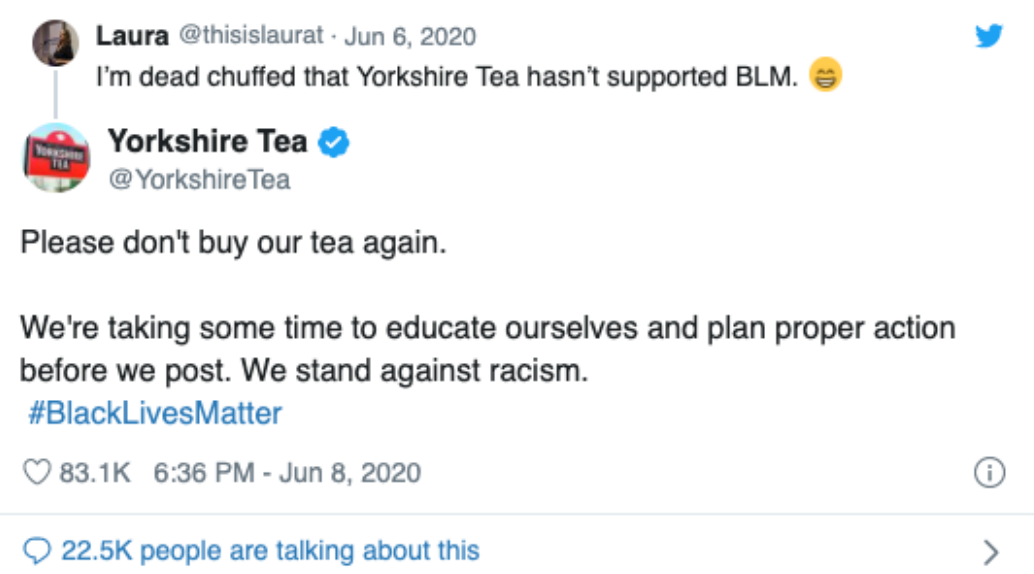

Figure 1. Yorkshire Tea's counter-marketing response to an anti-BLM Tweet.

"Subvertising" techniques [Rumbo, 2002] have been used by activists where a brand's slogans are used against the brand or a wordplay twist on a slogan to redirect commentary against the company to highlight unethical or unsustainable practices. Examples include the 2006 Green My Apple campaign from Greenpeace which used the familiar coloured iPod panels adverts but included photographs of electronic waste from the developing world [Greenpeace, 2006]. Environmental groups were concerned about Apple's use of known carcinogenic material in their computers at the time, such as organobromine compounds and vinyl chloride. As already stated, when companies themselves use similar techniques to raise a profile ironically, this is often within the rubric of corporate social responsibility (CSR). However, such initiatives have been criticised for being tokenistic or a form of "greenwashing" [Gatti, Seele and Rademacher, 2019]. There have been accusations of merely cashing in on a global crisis without contributing in any substantial way to its alleviation [Hill, 2019; Collin et al., 2020]. "Ethics" and "morality" in this 
sense can be inseparable from capitalist values and this in itself draws criticism. These strategies might intentionally or otherwise separate the brand from the contexts of capitalist and political structures and indeed the fundamental ethics underlying the UN Sustainable Development Goals (SDGs) and Responsible Research and Innovation (RRI) [Crilly, Zollo and Hansen, 2012; Roth et al., 2020]. As with the issue awareness campaigns of Ben and Jerry's and Starbucks, the tone also comes under critique with accusations of company executives not appreciating the wider structural contexts of the issues and the impact on individuals and communities. The ironic humour employed, particularly, can be seen as misplaced. The conflict can go deeper. Brands like Uber, included in the analysis section later, may have altruistic intentions with regards to COVID-19 but have been heavily criticised and indeed litigated for poor labour practices.

However, for those brands that seem to "get it right", we see individualism, light anti-capitalism and a type of anthropomorphism of online/offline identities. Social media has allowed new marketing spaces to open up, changing human relations where products enter the same world as celebrities (who are themselves brands) [Thomson, 2006]. ${ }^{1}$ Twitter, in particular, facilitates the language of consumer ethics tied into micro-political hashtag movements. The emerging language of social media assists the irreverence and contradictions of non-sales-friendly sales strategies. Depending on the degree of freedom corporations provide to their communications and marketing teams, the irreverence of anti-marketing can develop even further, displaying individualist activism within the capitalist paradigm. As Kozinets [2015] writes, brands have become "archetypal identities in themselves" [p. 149], sometimes taking on the cult of celebrity. Also, even in this era of collectives such as \#IBelieveHer and \#BlackLivesMatter - and institutional ethical marketing approaches shown earlier - individuals can bring more support to social causes. Twitter "heroes" tend to be individuals responding online either with revealed names to add authority, or tweeting pseudonymously, delivered as "mic drops" in reactions to global events of injustice. Although often distracting from the power of the collective, the concept of the hero still matters in our popular cultures [Solnit, 2019]. Cross-media influencers now enjoy a particular status and position, with Twitter, Youtube, Instagram, and TikTok the platforms of choice.

The activities are in line with irreverent, accelerated celebretisation and new creative forms of satire facilitated by social media, such as comedian Sarah Cooper lampooning Donald Trump's efforts to communicate, or miscommunicate, about the coronavirus on TikTok. Cooper took on the Trump persona by lip-syncing his most outlandish utterances during the pandemic, and her first and most popular TikTok is called How to medical. The fluidity of identity is evident. Cooper, a young, black woman and antithesis to the U.S. administration's interests at the time, somehow was Trump. The emergence of non-fungible tokens (NFTs) in the world of bitcoin, being both digital and physical artefacts and made more popular through extra publicity stunts on social media [Dylan-Ennis, 2021], are also within this domain of accelerated celebritisation. Also, the endorsing of brands by celebrities in a commercialised paradigm makes the brand more human [Thomson, 2006]. This is an extension of continued anthropomorphising of brands towards, I suggest here, posthumanising.

\footnotetext{
${ }^{1}$ There are COVID-19 testing sites in the U.S. sponsored by Pepsi ("near Walmart", as the signs helpfully inform drivers).
} 
One literal reading of posthumanist thought relates to the fear that robots and other technology will displace and replace human labour [Thomas, 2020]. Online, bots use AI algorithms to retrieve, analyse and connect and deliver deliberately fabricated news items. They are "amalgamations of code that mimic users and produce content" [Woolley and Howard, 2016, p. 282] and are deployed by various types of activists. This increases the posthumanism of online ethical marketing spaces. However, what is under inquiry in this paper is more subtle - the posthuman that emerges in consumption rather than particular types of fake identities created by technology itself. Our concern here is a softer, philosophical posthumanism where the signs have been in place for a long period already, rather than a harder, future transhumanist type which fears - or embraces - AI displacement.

There is a market dependency on the affect produced by consumerism and its emerging posthuman objects as they run through contemporary identity-formation to which corporations contribute in product design and in their marketing [Thrift, 2004]. Here a new ontology of place and space is formed [Thrift, 2011]. Brands have increasingly used a mix of posthumanism and irony, adverts as admixtures.

There are other examples of posthuman branding: the British juice and smoothie company Innocent - with Coca Cola the principal owners - asking customers to befriend their next smoothie bottle, then bin it as it knows too much; Nike asks runners to name their shoes on their tracking apps; the American diner company Denny's asks their consumers to make friends with its breakfast pancakes (Figure 2). The friendships, likes and follows on social media intermingle with the human-to-posthuman products. As described in the methodology section, the theoretical framework employed here uses science and technology studies (STS), following brands as entities within a sociotechnical network that capitalises on remote work and the separation from materiality of goods and services.

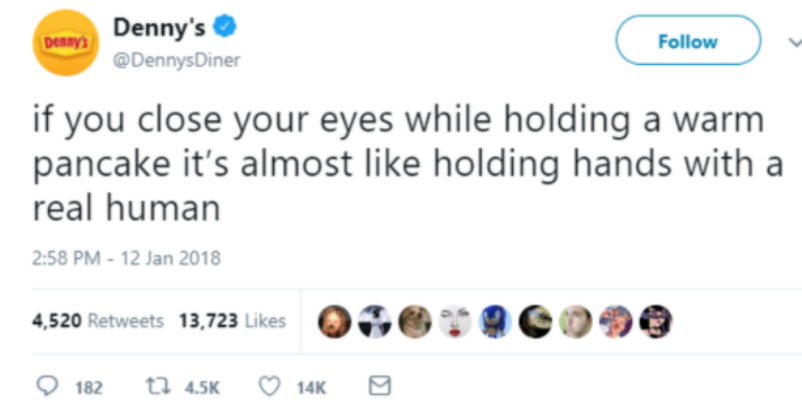

Figure 2. Denny's anthropomorphising of their brand.

Then, when SARS-CoV-2 arrived, there was self-appointed responsibility from private sector interests to provide health information in tandem with state public services, which was made starker by the huge global, cross-sectoral efforts to produce vaccines in 2020. The ironic online tricksters suddenly had become COVID-19 experts. This further shift online and increased hybridity of concepts meant certain implications for science communication. There is significant scholarship on how social media has weakened the dissemination of accurate information from a scientific perspective. Misinformation and disinformation 
through social media in particular have been well-researched prior to the pandemic [Ball, 2017; Chen and Cheng, 2020; Fontaine et al., 2018; Levinson, 2017; Scheufele and Krause, 2019]. COVID-19 has amplified this however [Krause et al., 2020; Scheufele, Krause et al., 2020]. The word-of-mouth nature of Twitter has been well recognised in this emerging landscape for corporate sales in particular [Jansen et al., 2009] and despite the tendency towards a traditional one-way approach of communication for social media strategies of science [Lee and VanDyke, 2015], the informality of this form of communication can facilitate a new breed of science communicator [Collins, Shiffman and Rock, 2016; Dalrymple, Young and Tully, 2016]. This makes coverage of accurate science through a pandemic even more problematic, but there is a sense also that an opportunity can be grasped as the world changes.

According to an Edelman [2020] survey of public opinion on the role of companies during coronavirus, there was a public appetite for brands to be participative and responsive to the crisis, rather than performing business as usual. "Show up and do your part... solve, don't sell... don't act alone... communicate with emotion, compassion and fact", as the report states in the conclusions to the study [ibid.]. If frontline workers were the real heroes visible in hospitals but also across social and mainstream media, a distant, depersonalised heroism familiar to us was needed more to those fortunate enough to remain healthy. Communicating about SARS-CoV2 and COVID-19 has significantly elevated the need for more nuanced science communication strategies from institutions of many types dealing with great global uncertainties [Scheufele, Krause et al., 2020]. Such models of communication have been several decades in the making [Davies and Horst, 2016; Holliman et al., 2009; Stilgoe, Lock and Wilsdon, 2014; Weingart and Joubert, 2019; Wynne, 1992].2 This nuance and deep engagement involve, among other things, paying close attention to the ever-changing modes of online communication. It is crucial to point out, however, that this new phenomenon of ironic consumption that Steak-umm or Yorkshire Tea employ is used as defence of both science and social justice and works in direct opposition to deliberate disinformation. Humour was understandably not the path taken by Reckitt Benckiser - the makers of Dettol - given the urgent, strategic communication required where lives were at risk. Clarity and authority were key with the company at the centre of this risk. Steak-umm fought against misinformation and disinformation from the sideline, as we will see later, but kept scientific integrity while using brevity and frivolity in its chosen style. These brands have been challenging society during the pandemic by having an element of Idoru's Rez while demonstrating a moral core as science commentator and science communicator.

Context: steak and disinfectants against COVID-19
In keeping with William Gibson, the much-quoted phrase of the pandemic period was: "It's like living in a sci-fi film". Media theorists noted this too [Chakravorty, 2020]. Successful brands set up narratives for consumers and products [Sanders and van Krieken, 2018] and the strangeness of the times allowed all kinds of hybrids to emerge that surpassed Hollywood. The continuing sci-fi disaster movie needed hero and villain motifs for commercial brands' storylines. Enter Donald Trump. Reckitt Benckiser, the makers of disinfectants Lysol and Dettol was

\footnotetext{
${ }^{2}$ The emphasis in contemporary science communication in Europe is PEST, public engagement with science and technology.
} 
prompted to make statements through various channels warning publics not to ingest their products, following a particularly dangerous word salad from the U.S. president where he suggested to teams of scientists the possibility of injecting disinfectant to treat COVID-19, later amplified on Twitter to also include bleach. At the same time Steak-umm, a packaged frozen meat company, was issuing advice on Twitter on how to verify accurate sources of COVID-19 online and how to negotiate the mission objectives of marketeers at a time "when people trust corporate food brands on twitter [sic] more than long-standing institutions".

Steak-umm and the detergent and disinfectant companies are further described later in this paper as examples of corporate interests as defenders of global health. Corporations as science communicators aligning with the great work that was already happening in other regimes of communication is a concern to those of us who value the prioritising of public policy-mandated communication, particularly in times of crisis and emergency communication where there are justifiable fears for market bias as much as there are fears of misleading information and disinformation. This was occurring in the U.S. in particular. For Reckitt Benckiser, the health advice was reactive, warning publics not to inject their products; for Steak-umm, it was proactive, as a meat packaging company did not have an obvious role in communicating Covid-19 risks, yet here was a marketing agency for this company warning against the dangers of fake news and misleading pseudoscience. These products had now taken apparent leadership roles in this inclusive science ${ }^{3}$ as some political and health policy leaders struggle to enact effective communication of swift action during the pandemic.

Here we have a non-sustainable meat company not likely to be associated with nutritious food and an ecology-threatening disinfectant company calling for citizen safety, sustainability and welfare and something more: science literacy in media. The clear irony here is that packaged frozen meat, disinfectant or detergent are not the obvious examples to communicate ethical and sustainable principles or set standards of healthy, green living to the world. In the hybridity of this ambivalent moment of post-corona living - with simultaneous voices of dissent from business-as-usual economics, while hoping to recapture the world as it existed pre-coronavirus - worlds have collided allowing different kinds of surrealist action against injustice and inequality. "We're a frozen meat brand", the Steak-umm Twitter account reminded its followers, "posting ads inevitably made to misdirect people and generate sales, so this is peak irony" [sic]. We will take up this point further in the next section - how an affect-based marketing incorporates the idea of the posthuman, while also promoting science literacy.

Theoretical framework: moralising, posthumanising brands and informational capitalism
"Moralising capital" here draws on the ethical marketing and often ironic strategies already outlined in previous sections. How we see the ethical in production and consumption is embedded within the way we view capitalism. The type of networked capitalism invoked here is a paradox, needing objects while also being post-Fordist; a capitalism that is both objectual [Nilson and Wikberg, 2021] and informational [Arvidsson, 2006; Arvidsson and Colleoni, 2012; Boltanski and Chiapello, 2005]. The paradox extends further as the immateriality of the process of

\footnotetext{
${ }^{3}$ Grand challenges requiring greater involvement from various publics have been the domain of the UN Sustainable Development Goals (SDGs) and Responsible Research and Innovation (RRI).
} 
building a brand relies on the conceptual and virtual network, but also the ethical surplus [Arvidsson, 2006, citing Lazzarato, 1997] created by the branding of real objects, that is the aesthetic, the team-building and identification with a group, and ultimately also the unpaid labour that can result. This conflicting, ethical meaning-making extends out to environmental and social justice issues within society.

STS media scholars have reimagined digital spaces as particular objects with new posthuman identities where networked relations might prevent the continuance and amplification of traditional, racist, capitalist and White European male-dominated systems that currently exist online [Braidotti, 2013]. Aligned with the panic of the pandemic, systemic racism remained in digital media not just in content but in design [Benjamin, 2019].

Media theorist Nick Couldry [2012] states that the cultural landscape of advertising and messaging is a complex web of interaction between strategists and publics where there is a public socialisation effect resisting strategic communication. The emergence of online communities increases fluidity, hybridity and hyperconnectivity [Davis, 1998; Fournier, 1998; Giesler and Venkatesh, 2005; Peters and Jandrić, 2019]. There is also increased informality — the brevity and emerging lexicon of Twitter further facilitates the flattened expertise as a new form of word-of-mouth among these online entities and their human followers [Jansen et al., 2009]. Humour, satire and irony in meme culture is one of the results, as is also the case for science communication [Joubert and Wasserman, 2020; Riesch, 2015].

The Steak-umm and disinfectant company examples — to which we will return are examples of an emerging moralising and humanising capital. To further elaborate on "humanising": this aspect can be an extended self [Belk, 1988] or a product given human attributes [MacInnis and Folkes, 2017] or a more complete brand personification [Epley, Waytz and Cacioppo, 2007], even made to seem "cute". Sci-fi visions of the future and elements of cuteness are part of a posthuman, informational capitalism [Campbell, O'Driscoll and Saren, 2010; Campbell, Deane and Murphy, 2015; Kozinets, 2008; Kozinets, 2015]. The added anthropomorphic element of the cute and the inviting is of course how brands build up more trust and therefore increased credibility.

One other impact of this increased online hybridity is the increased posthuman of social digital interaction, where the physical is formed in the online manifestation to extend the offline persona [Couldry and Hepp, 2017; Kalpokas, 2019]. Non-avatar entities are created, interacting with human cyphers online. There is then a further conceptualising of anthropomorphising that places a "thingness" of the product and the brand in the realm of conversations with humans with both physical and digital identities intertwined [Couldry, 2012; Horowitz, 2012]. After all, consumers appear to still want the smell of frying steak and clean disinfectant! Posthumanist and STS research tracks the network of action here by granting the brand a specific agency within this consumer-consumable relationship. This develops a further paradox - a brand which wants to be free of capitalism. Such a cognitively dissonant position seems at this point to be possible. The brand becomes separated from the product but perhaps only as a conceptual step. The materialist links to product remain, at times hidden, sometimes accentuated. 
As these entities become networked as nodes of hybrid identities online, a concern might be the potential of dehumanised responses to COVID-19. However Lysol and Steak-umm - whatever the motives - display a duty of social conscience. There is however concern about dissemination of scientific information: there is already low credibility in Twitter content as verified by health officials [Shao et al., 2018], and questions over the suitability of social media for accurate health advice [Collins, Shiffman and Rock, 2016; Moorhead et al., 2013]. While some companies like Steak-umm were careful about directing publics to legitimate sources, for others the links to sources were not so clear. Brands that offered something new while still cognisant of the global situation fared better in public opinion [Kantar, 2020].

In essence, satire and irony, playful posthumanism and other devices of humour emerge into these liminal spaces and scientific and political vacuums. On their own, these processes have been in play a long time - CSR, ironic advertising, anthropomorphising/posthumaning products (for instance, motorbike and car enthusiasts give their vehicles names).

Playing with concepts of animism or extra-human is not new for entertainment or advertising [Campbell, O'Driscoll and Saren, 2010]. What is changing is the increased number of actors and relations creating these new types of identities and impacting on technological information and public interaction with science, which is most critical in times of a global crisis that demands urgent action. While there is an increase in the use of automation - mainly algorithms, bots and other AI - to communicate science, there is a parallel disintermediation of scientific expertise, as patients and publics use online resources as their first steps of information retrieval much if which is not sanctioned by the WHO or other health agencies [Fontaine et al., 2018]. Where health agencies do not match the humour, irony and ultimately the engagement levels of the Twittersphere, corporations have shown how they can replace this disintermediation and edutainment. The nodes in the networks are spreading out wider, where cocoons and bubbles of quarantined publics grow, physically distanced, disenfranchised and craving more human attachments in spaces that have traditionally not been human, and now also taking on the role of science communication champions. It is no wonder that shortly after the initial terminology of "social distancing" was put into common language in early 2020, the $\mathrm{WHO}$ - unsuccessfully - attempted to change the term to "physical distancing". Social interaction has arguably increased.

What we are now seeing is an acceleration and a convergence: the evolving concept of product as a posthuman being in and of itself, moralised, taking on the ethics of co-opted expertise, and where there is equitable status for both marketable expertise and scientific information and such experts almost impossibly attempting to address new inequalities, inequity of information dissemination and online polarisation.

Methodology

This study is informed by STS and science communication literature. STS follows relations or networks which Law describes as methods that "not only describe but also help to produce the reality that they understand" [Law, 2008, p. 5]. As Felt [2020] found in the public health communication of obesity — and Mol [2003] in the identification and diagnosis of arteriosclerosis - we more easily trace out the 
wavy lines that connect and resist collectives of body, object, ephemeral technology and concept if we see the nodes of each sub-network as performance.

In tracking relationships along performances made public, outward communication to publics/consumers from companies were analysed rather than internal or stakeholder communications. The performed network approach assumes brands are relationships with exchange and added value [Evans et al., 2008; MacInnis and Folkes, 2017]. In the dataset, I used a spread of brands associated with the following types of company:

- Manufacturing

- Retail

- Consultancy and professional services

- Pharmaceuticals and hi-tech

- Public relations and advertising

- Media and entertainment

The companies behind 100 popular brands were analysed in total. Brands were chosen on the inclusion/exclusionary basis of familiarity as an everyday brand, their increase in market popularity during the pandemic and their newsworthiness for public engagement during the pandemic. Forbes' top brand listings for 2020 were also included in the criteria ensuring the inclusion of Asian and African brands. Although included, there was less emphasis on the pharmaceutical sector, which in many cases will have an advanced role in communicating science. While media organisations were included, news media were not, given their primary mission of information transfer. National and cultural contexts of target brands were included in the analysis.

Public statements from the companies on their responses to COVID-19, as well as advertisements, memes or social media artefacts, were selected for analysis. The timeline for analysis of brands' information about coronavirus was between February-October 2020, and then further analysis of each brand's advertising or media output by Twitter, websites, videos or from the branded products for two years previously.

For each company, the following were analysed:

- Company statements

- Content of tweets

- Company ad campaigns referencing Covid-19

- CSR policies and responses to the pandemic

Once preliminary analysis of a significant collection of randomised companies was complete, patterns began emerging with regards to how the companies communicated about COVID-19, which was then extended to all 100 in the dataset. 
The following Google and Twitter search words were used: [brand name/company name] + "COVID-19", "health information", "anthropomorphic products", "posthuman brands", "post-human brands", relief", donate/donation", "PPE". This empirical part of the study attempted to track and map how Twitter accounts align with a material product. Twitter was chosen over Instagram, Twitch, Snapchat, TikTok and other social media for its use of a relative amount of text as well as images. Multiple devices were used to reduce search engine bias. There are some Twitter quotes placed in the analytical sections for illustrative purposes. Approval for each individual and institutional Tweet represented was sought through the standard researcher university ethics process and approved and signed consent for revealed Twitter identities granted in each case.

Taking standard approaches such as Altheide [1996] into account, a deductive set of codes was established from theoretical discourse and debate, while a set of inductive codes emerged through analysis. Five coding categories emerged from the literature which combined into a preliminary codesheet. These were deductive categories that demonstrated how current events in popular marketing culture and literature were coalescing with respect to how brands might "communicate" science during the pandemic, and also mapped out the theoretical construct shown in previous sections (Table 1). The ideology was accepted to be within informational capitalism and market logic and its influence on strategic and social media logic [Siapera, 2011; van Dijck and Poell, 2013]. The inductive analysis in the datasets coalesced around 6 categories that were re-tested during a secondary analysis, to strengthen decisions on coding. These aided the mapping out of the analytical sections, identifying a typology of the chosen companies and the inductive codes for a rudimentary quantitative assessment of this typology for each company or brand. These inductive categories were entertainers, influencers, health informants, active good citizens, science/media watchdogs and human-to-posthuman brands. Further justification for categorisation boundaries is given later in the brand analysis section.

The next sections will briefly look at two extraordinary cases of communicating COVID-19.

Table 1. Coding schema.

\begin{tabular}{|ll|}
\hline Deductive coding from theory & Inductive categories from data analysis \\
\hline Moralising capital & Entertainers \\
Reflexive humour/ironic marketing & Influencers \\
Brand as human/posthuman & Health informants \\
Corporate replacement mediation & Active good citizen \\
Networked nodes communicating science & Science/media watchdogs \\
& (Post)human brands \\
\hline
\end{tabular}

Exemplar case 1: disinfectants against COVID-19 and Trump
Detergents and bleach became weapons used against coronavirus during the global pandemic. On April 23 $3^{\text {rd }}, 2020$ - during one of the many live speeches Donald Trump presented to the American public with leading health advisers and scientists flanking him or standing behind him — the U.S. President began to ramble about the possibilities of injecting disinfectant or using light to treat COVID-19. Two Reckitt Benckiser Twitter accounts of the company, @RBanima 
and @discoverRB, fielded may queries for several days. The company released a statement to contradict the president on April $24^{\text {th }}$ [Reckitt Benckiser, 2020]. The statement read: "As a global leader in health and hygiene products, we must be clear that under no circumstance should our disinfectant products be administered into the human body (through injection, ingestion or any other route)" [emphasis in original]. Clorox, the maker of bleach and market competitor to Lysol in the U.S., also released a strong statement contradicting the U.S. president.

The New York Poison Control Centre began reporting cases of disinfectant injections and also issued its own statement (Figure 3). Trump's defence of the then largely untested hydroxychloroquine drug to fight against coronavirus similarly prompted science communicators to set the record straight on what was known to science and the limits to COVID-19 treatment at that stage.

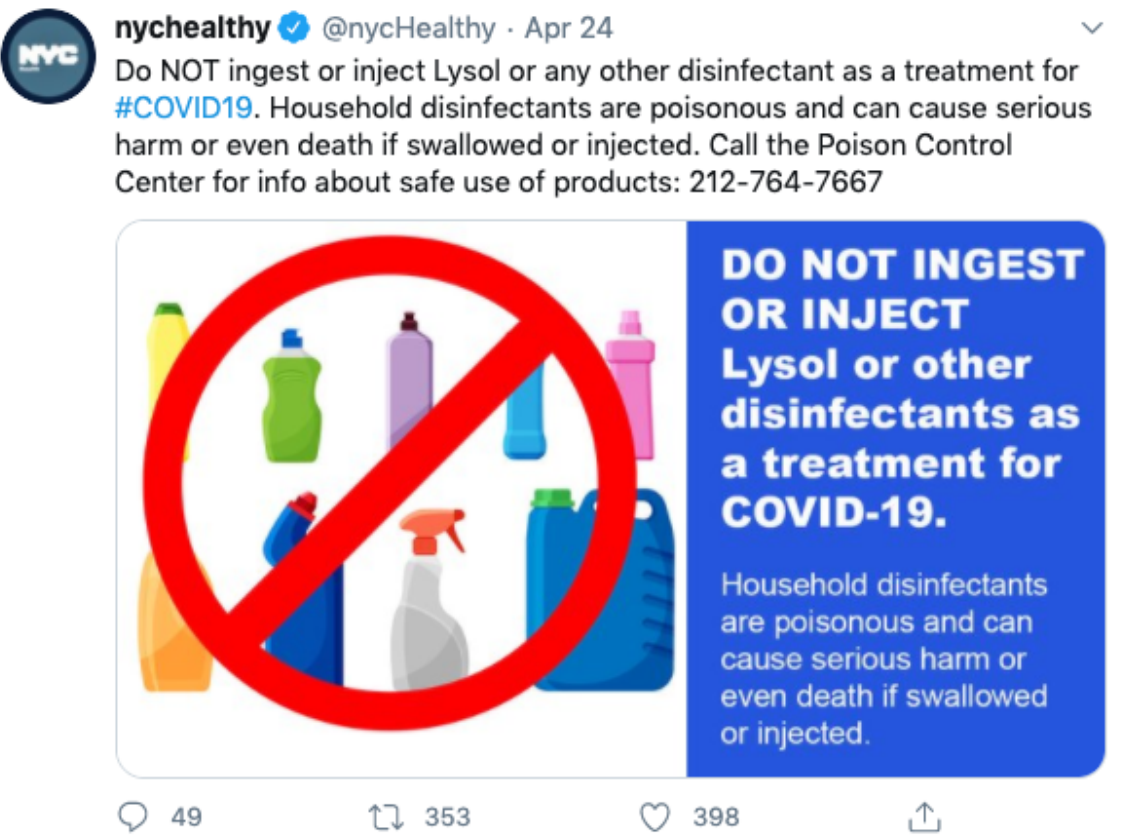

Figure 3. New York City Health official Twitter response to Trump's "disinfectant speech".

This rather historic moment within many others during the pandemic was widely ridiculed, inspiring several memes, some also using images and videos of top scientific advisors, caught at the top of a political system that thrives on chaos and confusion. Drinking Dettol or Lysol had replaced "drinking Kool-Aid" or "eating Tide pods" as the standard derisory description of political opponents.

Reckitt Benckiser had fought its own legal battles against Proctor and Gamble, which owns the Clorox company. A long-lasting dispute has taken place between both organisations with regards to the interpretation of whether or not an odour removal product was in breach of Registered Community Design regulations, which is an EU-wide intellectual property mechanism. The image in Figure 4 demonstrates this battle playfully, anthropomorphising Lysol and Clorox as heroic knights locked in combat. However, in early 2020, both companies were united swiftly counteracting Trump's pseudoscience, issuing strong statements contradicting the U.S. President. 


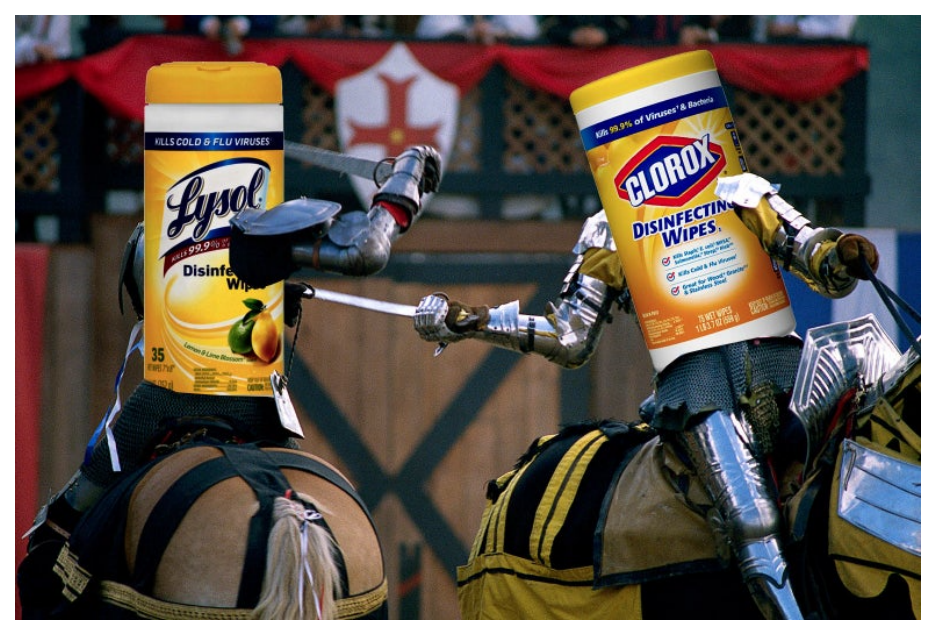

Figure 4. Lysol versus Clorox. Photo illustration by Derreck Johnson. Images via Richard T. Nowitz/The Image Bank via Getty Images plus Reckitt Benckiser and Procter \& Gamble, reproduced with permission.

While the battling knight image is a one-off representation, there is a darker history of bleach as represented by another anthropomorphised character, Clorox-chan. Bleach has been used in both teeth-whitening and suicide attempts and Clorox-chan is a cartoon drawn in the style of sexualised anime often appearing in Asian meme cultures to warn people of the dangers of ingesting bleach. Both types of anthropomorphised representations were created by designers not connected with the company in each case and are unlikely to be embraced as representations from a corporate perspective given their critical DIY nature (and the presence of misogynistic imagery in the case of Clorox-chan).

Exemplar case 2: "Steak-umm Bless"
Steak-umm is a frozen meat company under the auspices of Quaker Maid Meats Ltd., a brand that has gained attention over the years for its edgy communication style but was little-known outside of the U.S. until the spread of COVID-19. In a series of tweets, science and media literacy were analysed and discussed in sophisticated yet accessible terms, condemning disinformation. The Twitter account achieved a type of cult status among followers as demonstrated in one of its mock-iconographic images shown in Figure 5.

In 2017 when Quaker Maid Meats made a decision to target a younger market with one of their brands Steak-umm, their marketing company Allebach

Communications seemed edgier than was the norm. By mid-2020, Steak-umm was the defining hero in a sea of chaos in U.S. health policy during COVID-19. Nathan Allebach, the Creative Director, took on the mantle of defender of science and literacy as the mouthpiece of Steak-umm. In an interview with the Wall Street Journal, Allebach claimed he had tried to avoid the polarisation that is inevitable on Twitter [Andrews, 2020], but felt compelled to add to meaningful discourse about coronavirus and how information is transmitted. The voice of Steam-umm said he wanted it to be:

like... a family-owned frozen meat company built by the working class, then me trying to personify it based on those features, my own thoughts, and an adaptable human-esque style that feels like someone you know (Allebach in an interview [Andrews, 2020]). 


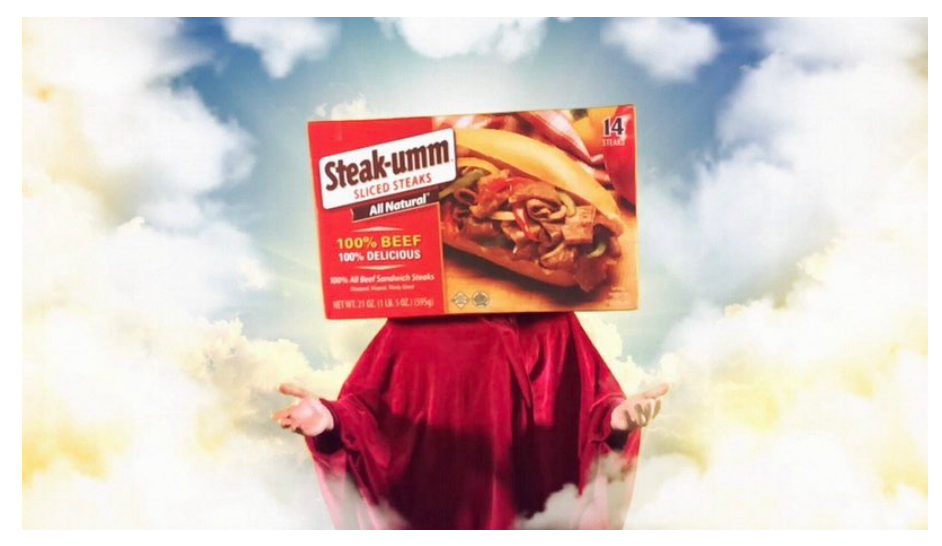

Figure 5. Steak-umm's messianic iconography (published with permission from Quaker Maid Meats).

Allebach Communications typically used quirky brand distinction of meat puns and omitting capital letters and regularly signed off tweets with the knowing catchphrase "Steak-umm Bless".

Steak-umm under Allebach's digital marketing guidance has become a champion of social justice with other socially conscious brands. However, it is not without its critics [Houck, 2018]. Mixing social causes with commerce has potential for a toxic hybridity that just scratches the surface of the problematic of capitalism as a wide, open field where heroes are constituted from filmic and cultural underpinnings. However, a fanbase has built up with the Twitter account being so popular that a bot has claimed to be the real account. Steak-umm has already been a subject of social science research, which focused on its leadership role and its use of humour [Bogomoletc and Lee, 2021]. Steak-umm, under Allebach, demonstrates unusual reflexivity, as it challenges ineffective media coverage of informed science and social justice issues and supports the need for critical thinking publics but it also goes several steps further in calling out corporations themselves - of which it is a representative - and Twitter for their role in misinforming publics and the form of capitalism that allows "it", Steak-umm, to suddenly be seen as a posthuman expert in science and media affairs. In an April $8^{\text {th }}, 2020$ tweet, the Streak-umm account identified that a brand could only make these concepts go viral while individual tweets from a person would not succeed. The heroic individual as brand, not human. In April 2021, the Steak-umm account achieved even greater popularity and notoriety - when challenging the epistemological position of the U.S. science communicator Neil deGrasse Tyson following his tweet on the topic of science and truth. This is a significant scaling up of critique not just of corporate control of information and misinformation but of science communication itself.

In its post-corona incarnation, Steak-umm fits neatly into the PEST-era science communication paradigm that resists deficit model approach of preaching and decrying those who have alternative beliefs (Figure 6). Through the voice of Allebach Communications, Steak-umm challenged other brands to offer the same level of science and media literacy advice. Clorox played it straight while Steak-umm did comedy.

What is clear in these strange times is that these Twitter interactions do not merely show marketing or social media personnel represented as a cypher for a company 


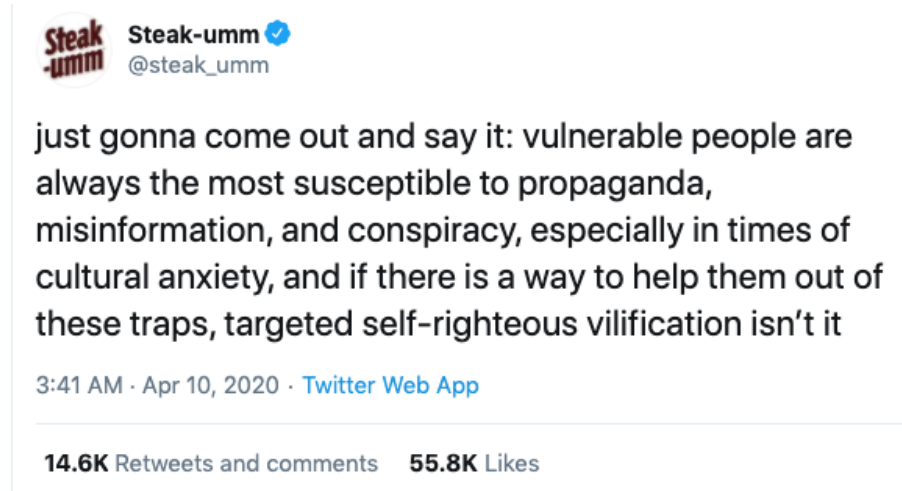

Figure 6. Steak-umm on vulnerabilities and misinformation.

Company or brand "faces" in a new era: a typology of COVID-19 corporate communication
This section will outline a typology that emerged from the analysis of one hundred familiar brands and the companies behind them. I have mentioned how leadership - so prized as a concept in the corporate world — was lacking in preparing for, mitigating against and preventing COVID-19. The cultures of mediatisation that has accelerated since COVID-19 lockdowns has created the situation where the interaction and interconnectedness of formerly disparate institutions and concepts has led to sub-political and apparent anti-capitalist action from private companies, as well as an emergence of playful cyber-human identities.

Table 2 shows the categorisation of types of persona or face that a brand projected at various times during the early stages of the pandemic in 2020, mostly on social media but also using other advertising methods. Brands demonstrate relationships, exchange and value [Evans et al., 2008; MacInnis and Folkes, 2017]. Note that while they are archetypes, there is a fluidity to how a company or brand expresses them. An individual company can take on multiple categorisations, as shown in Figure 7, but from a public perspective, one dominates at a time. Some companies or brands exhibited multiple engagement faces but only Steak-umm displayed all six.

Within the dataset, the typology of faces that each company brand used in different contexts in communicating about COVID-19 or coronavirus forms a spectrum. One side (entertainer) relates about standard production processes of that company and/or brand and the further we move out to the other side (human-to-posthuman), we see issues raised or activities that are more socially conscious and go beyond the normal production or sales discourses. The face a company used also depended on age profile and other demographics of the target market.

Let us look at some of the differences between these public faces. The entertainer side of how a company communicated during the pandemic utilised a new slogan 


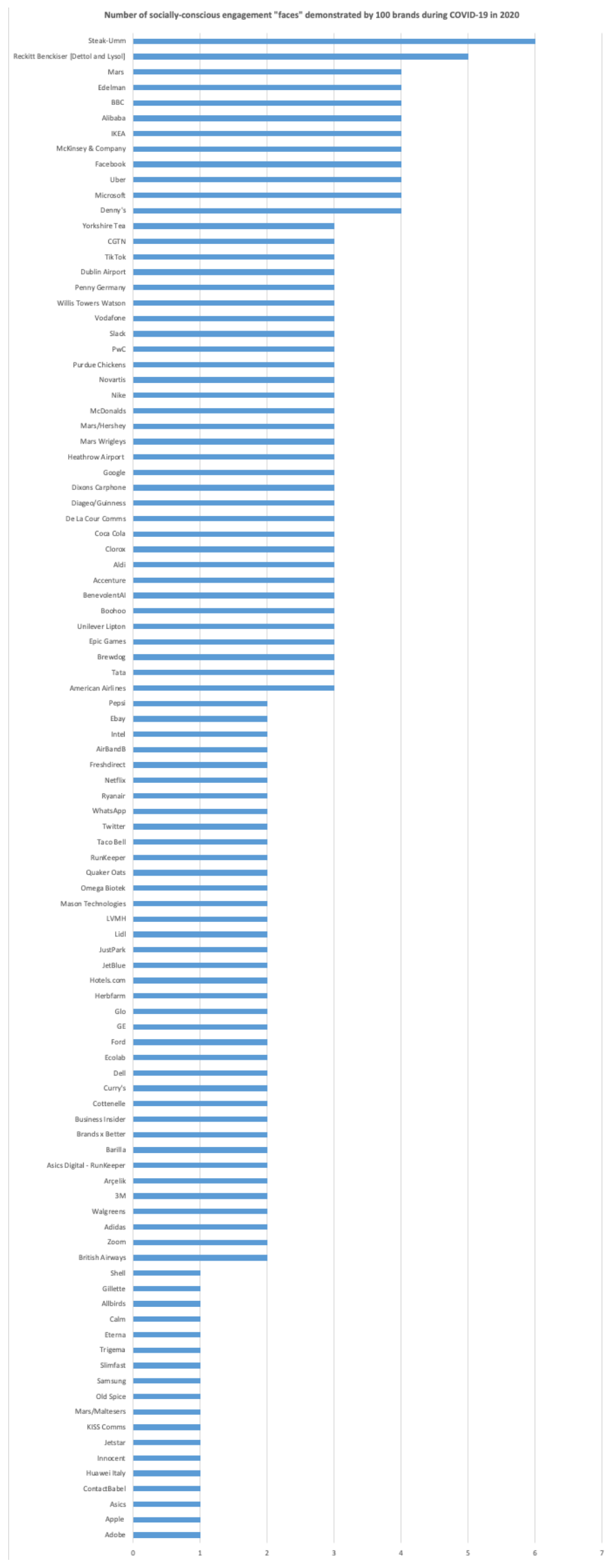

Figure 7. Number of types of company faces of COVID-19 engagement demonstrated in 100 brands analysed. 
Table 2. Brand "faces" during COVID-19 and the characteristics that define each face. Companies and brands as collective identities can show multiple faces.

\begin{tabular}{|c|c|}
\hline $\begin{array}{l}\text { "Faces" of brands or } \\
\text { companies }\end{array}$ & "Facial features": what publics see from brands during coronavirus pandemic \\
\hline Entertainer & $\begin{array}{l}\text { Catchy new slogans, or a spin on old one in marketing campaigns; } \\
\text { social-media slogan/hashtag-driven; marketing gimmicks of } \\
\text { solidarity; significant use of humour and irony }\end{array}$ \\
\hline Influencer & $\begin{array}{l}\text { While still a market focus, action is practical towards COVID-19 } \\
\text { prevention/treatment as well as discursive; it may be some change in } \\
\text { production that is not too far outside their usual domain eg } \\
\text { pharmachem working on a vaccine; pharmacist doing COVID-19 tests, } \\
\text { clothes manufacturers making PPE; possible science communication } \\
\text { advice }\end{array}$ \\
\hline Health informant & $\begin{array}{l}\text { Science communication advice somewhat at a remove from the brand; } \\
\text { providing employees and customers with constant, up-to-date } \\
\text { messages on physical distancing and hygiene, or the public and social } \\
\text { media followers on coronavirus and COVID-19 }\end{array}$ \\
\hline Active good citizen & $\begin{array}{l}\text { Going beyond current production and markets to do altruistic deeds } \\
\text { for publics, such as supplying food or goods to patients or healthcare } \\
\text { frontline workers; companies without the required production } \\
\text { processes making hand sanitisers or PPE }\end{array}$ \\
\hline $\begin{array}{l}\text { Science and/or media } \\
\text { watchdog }\end{array}$ & $\begin{array}{l}\text { Guiding customers, followers and publics towards better choices of } \\
\text { media, differentiating between authenticity and fake sources, between } \\
\text { science and what has been categorised as pseudoscience; can be a } \\
\text { realisation that media and science literacy are tightly bound }\end{array}$ \\
\hline Human-to-posthuman & $\begin{array}{l}\text { The product itself as brand and concept demonstrates playful human, } \\
\text { non-human or posthuman dimensions, interacting as its own entity on } \\
\text { social media; loosely linked to entertainers }\end{array}$ \\
\hline
\end{tabular}

or a spin on an old one that spoke directly to COVID-19. Examples were Cottonelle joining in with jokes about toilet roll shortages with \#ShareASquare; or McDonald's famous arches separated in an outlet in Brazil; Wrigley playfully advertised fake garlic-flavoured chewing gum reminding people to \#KeepYourDistance; Netflix putting spoilers of top shows on billboards in an effort to keep everyone at home. Media providers like BBC used entertainment with edgy humour and jokes about the pandemic, aligning with meme culture online. Confectioners such as Mars used slogans humorously like \#StayAtHome in their campaigns and airport tweets used levity in billboards and Tweets. Figure 8 demonstrates a coronavirus-inspired art exhibition.

Influencers exhibited a clear market imperative but with some production changes aligned with light science communication advice. Health promotion was aligned with brand positioning with tools designed to have impact requiring extra marketing effort in terms of changes of approach. Often there was focus on Twitter marketing to gain extra social capital status, or changes in physical infrastructure, or new business practices. This brand face did not utilise billboards or was as involved as producing PPE but spoke directly to COVID-19 without active participation. Such companies positioned themselves as market leaders as well as health communication leaders. As would be expected, the pharmaceutical companies like Pfizer, Omega and Novartis were involved in either the development of treatments, testing kits or a vaccine demonstrate declare a change in production. There is commercial benefit here and this also can make these elements of the categorisation aligned closely to active health informants. 


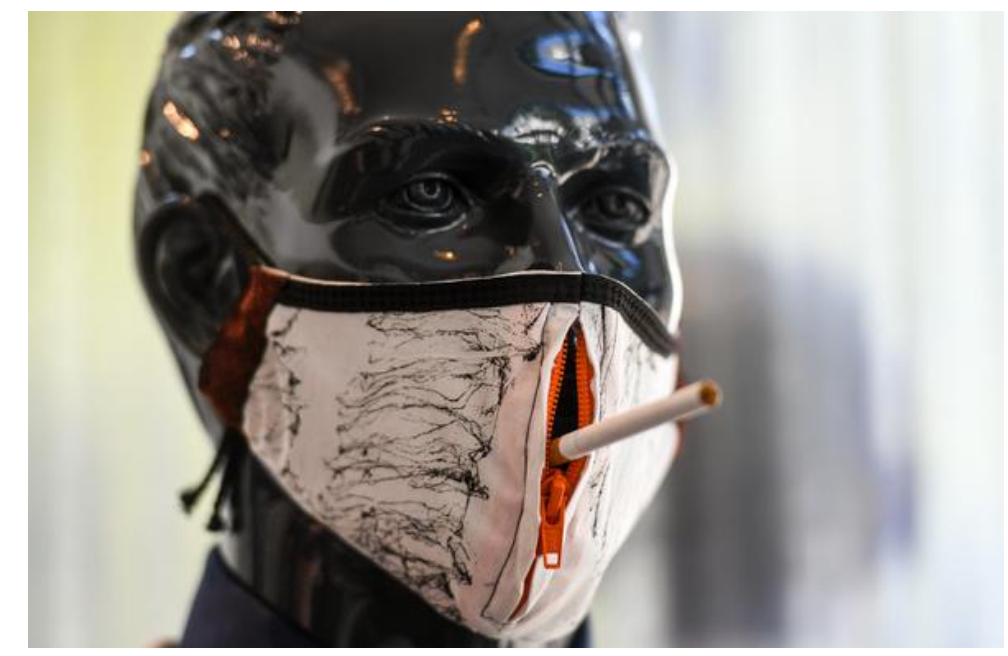

Figure 8. A fashion face mask on display as part of Wolfgang Schinke's exclusive collection of couture COVID-19 fashion in collaboration with Pierre Zielinski. The expo was held at Schinke's studio in Krefeld, Germany in April 2020, during the pandemic. 10\% of revenue was donated to the 'Krefelder Tafel' social project. The image captures the risqué, adventurous, and dangerous dichotomy of the healthy and unhealthy, as well as the ironically responsible action against COVID-19 that some of the chosen brands in this study also exhibit (Photo by Ina Fassbender/AFP via Getty Images, reproduced with permission).

The Ford company can be considered an influencer by publicly advertising that the company will allow deferred payments for up to 6 months on newly purchased cars in the U.S. as part of its \#BuiltToLendAHand campaign as the country fell into COVID-19 recession. Nike also offered concessions on its merchandise but used entertainment in glossy adverts for its "Play Inside, Play for the World" campaign.

The straightforward science communication advice given by companies using the health informant face are somewhat at a remove from the brand. While IKEA creatively presented home living in a new way during the \#YoMeQuedoEnCasa campaign - the company's entertainer face - they also provided employees and customers with constant, up-to-date messaging on physical distancing and hygiene measure, as did airports and supermarket chains. Media companies such as BBC and NBC naturally provided this public health role. The unexpected champions here were the "sharing economy heroes" AirBnB and Uber (a paradox when its drivers do not experience this "sharing" [Amnesty International UK, 2021]), and as shown earlier, Steak-umm. Hitech companies such as Ebay, Slack, Twitter and WhatsApp claimed that they direct users to authentic, legitimated science content although the latter two sustained heavy criticism that their efforts were not enough, given their prevalence in the spread of misinformation.

The active good citizen face was the most prevalent and one could claim with some justification that in times of crisis - whatever the ideological standpoint - the most obviously common phenomena to occur among corporates was the swift response to help however possible in the relief efforts. Many companies were highly influential and contributed to a "war effort" - which was an erroneous definition given the complexities and connectness we all share with the microscopic world [Connolly, 2020]. However the war metaphor used here mobilised to change production practice such as General Motors manufacturing 
PPE. Ebay pledged $\$ 100 \mathrm{~m}$ in support of startups connected with the pandemic. Companies in this category demonstrate evidence of production of free products, aid or services, rather than a change in commercial production.

Some were accused of marketing gimmicks. While Fashion houses such as Prada and Louis Vitton were praised at the stage in the coronavirus timeline where masks were acceptable throughout Western value systems, while at the early stages of the pandemic, the fashion retail outlet BooHoo received significant backlash for developing fashionable face masks that did not pass minimum requirements to prevent the spread of coronavirus. BooHoo attempted perhaps to display an active good citizen face here but became "relegated" to entertainer because of lack of effort in making correct masks.

What characterised the science and/or media watchdog face was companies guiding publics towards better choices of media, differentiating between authenticity and fake sources, between science and categorisations of pseudoscience. This aligned with notable individuals who performed this role on Twitter. Ebay, for example, checked for bids on their popular auction platform which misused science or capitalised on the disaster and removed them. While the health informants developed or pointed publics to authenticated science content, the science and/or media watchdogs actively taught and promoted media literacy involving science. There was evidence in the realisation that media and science literacy were tightly aligned to each other. As already been demonstrated, Steak-umm is a prime exemplar in this category, and Reckitt Benckiser, perhaps more reluctantly so. Dublin Airport engaged in online arguments with an Irish right-wing conspiracy theorist who had organised protests against masks and physical distancing, and tweeted: "One of the few businesses that seems to [be] operating as usual is your business of peddling untruths".

There are echoes in this face categorisation of a corporate version of Fahy and Nisbet's [2011] (self) categorisations of science journalists as watchdogs. Some companies positioned themselves as champions of sound science providing authenticity on COVID-19 and coronavirus facts while fighting misinformation, mostly on social media. Media-oriented enterprises such as Edelman, De La Cour and McKinsey were in this space. Social media companies like WhatsApp and Slack got involved in literacy campaigns, although again, the former was accused of not going far enough.

There are some apparent overlaps in these public faces, but mostly there is an outwardly-perceived distinctive function to each face. Although a brand can have several faces, the typology shows that one is prominent at any given time. Influencers appeared to look for longer-term impact beyond the immediate crisis, so for example vaccine production rather than PPE production or donation. On the other hand, active good citizens took an ideological stance to help society at large, linking COVID-19 response to their wider CSR strategy. Influencers modelled their actions on individual social media influencers and in so doing used social media as their primary field of action, while active good citizens demonstrated - albeit also through social media - action in the real world. Influencer action may be discursive only, or involving practical measures such as changing payment measures employees or offering free food to health workers. If influencers' action was seen as practical measures towards COVID-19 prevention or treatment as well 
as being discursive, it may be represented by some change in production that was not too far outside their usual domain of operation. Examples included pharmaceutical companies working towards a vaccine, pharmacists conducting COVID-19 tests or clothes manufacturers developing PPE. By contrast, AGCs needed to completely repurpose production processes. We could say crudely that the "bottom line" is an objective for influencers, selling something differently during the pandemic while $A G C s$ acted voluntarily, seemingly altruistically. Influencers in the individual online sense "influence", in that they promote extensively, and so a company demonstrates an influencer face when it mobilises people. This is where the influencer category is close to entertainer - it can be influential without changing production processes. TikTok and Zoom were influencers even without having to do anything extra - the forces of the changing times and people's needs meant that the influencing is done for the company by publics, or "customers".

The furthest "out-there" public face for brands was the human-to-posthuman. These captured fully our theoretical framework of hybrid identities tracing out new relationships online that play with the idea of identity in terms of growing acceptance of a nonhuman world in society and policy. Two most obvious examples that employ a posthuman ethos are the artificial intelligence (AI) developers like BenevolentAI, which actively use such technologies to develop treatments for COVID-19 health complications, and Alibaba which assisted in rapid COVID-19 patient diagnosis for ventilator use. Of more interest here though is the stretching of online human personas that display new forms of communication in what Couldry [2012] calls a media manifold. The product itself as brand and concept moves from human to non- or posthuman dimensions, interacting as its own entity on social media. The category is loosely linked to entertainers. Animals even formed part of the hybridity. Mars Inc. highlighted the care of pets and how communities of animals connected with humans as an important element of dealing with lockdown. Purdue Chickens even demonstrated the "humane" ethics of animal care of their "stock" before slaughter. But it is in the anthropomorphising brands that we see an aligning with a posthuman attitude, often with irony and humour. Allebach Communication's curation of the Steak-umm Twitter account perfectly demonstrated this. "When you're trying to love people", stated one caption on a Steak-umm Twitter image, with a human hand reaching inside a cage to touch the paw of an otter whose eyes are closed, "but you're also a brand and have boundaries". Figures 9 and 10 demonstrate examples on Twitter.

In contrast, another U.S.-based restaurant company, Denny's, decided on the opposite social media strategy to Steak-umm: @DennysDiners tweets had previously used humour, but during the pandemic decided to avoid this approach given the serious circumstances. Interestingly, the increase in ironic branding is still an outlier and contradicts a key finding in the Edelman survey, where $57 \%$ did not want humour. This survey focused on a serious topic, so it could be argued that there is a bias in the question. This has implications for the engagement with critical scientific information, but one suspects that such surveys place "science" into a formal frame that resists association with humour and satire.

Dublin Airport, like Steak-umm and Yorkshire Tea, demonstrated a strong persona in their Twitter exchanges and each of them projecting the appearance of an entity capable of breaking free of capitalist bonds and challenging inequalities and ineffective coverage of science. They feed off their ironic position and the 
sure, when I say "everyone should study philosophy because with practice and repetition you learn to tap a kind of hyperaware metacognitive state that is a net benefit in all disciplines" you all roll your eyes but when the anthropomorphized meat product says it you get on board

Steak-umm @steak_umm
critical thinking beef tips, A THREAD
critical thinking is not a singular skill. it's a constant state of
metacognition, measuring evidence, and recognizing when to defer
to experts. it's analyzing this tweet's substance, motivations,
credibility, and source, not just reading it
3:52 AM - Apr 24, 2020
1.2

Figure 9. A Tweet from Laura Lorson, news editor, Kansas City area radio host and one of Steak-umm's many Twitter commentator/fans.

A Miss Roy

A. @Ghani_Bewdi

I'm more dettol than human now.

7:39 PM · Mar 29, 2020 - Twitter for Android

16 Retweets $\mathbf{5 0}$ Likes

caroline henry @cazhenry·Apr 14

Replying to @DublinAirport

How do $u$ high five an airport ?

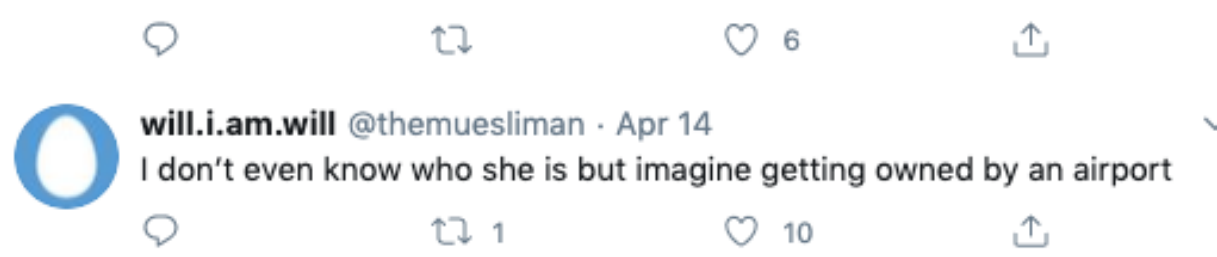

Figure 10. Three examples of anthropomorphising an entity associated with a brand via Twitter, and in the process placing within a broader posthuman frame. The first shows a humorous relationship with Dettol with the extra cleaning rituals, reminiscent of Flann O'Brien's The Third Policeman where the eponymous hero cycles to such an extent that he has more molecules of bicycle than human. The other two tweets appeared during an online spat between Dublin Airport and an Irish right-wing COVID-19 denialist.

knowingness of public expectation as they, as both brand and product, fight for science and social values. The crux of it all is the centrality of these networked identities that are a combination of brand associations emerging in a grounded online space. There is even a hint of being community-based, local. In Steak-umm's 
case, it is the creative social media manager, the brand as entity, the brand as product and even the frozen steak itself. This also works for tea, airports, bleach and other commercial products.

Conclusion
This paper has made some modest steps in analysing the connections between anthropomorphising brands, an emerging posthuman ethos in consumption and new forms of science communication that invoked irony and humour during the COVID-19 global lockdown. The study explored online representations of brands and how science communication occurs in these new interstitial spaces where new online identities, human and non-human, are created. There are aspects of ironic advertising or anti-advertising in the methods employed by social marketing teams to communicate about COVID-19 or address misinformation or disinformation. I have placed this phenomenon within the frame of a "moralising capital" by corporations that use specific forms of corporate social responsibility, and further, toward a playful posthumanism within hybrids of anthropomorphised products and brands. The more playfully ironic and humanising the brand identification is, the more it broadens out to a wider range of social capital. These are hybrids of consumer, brand and objectified product interacting with irony and humour.

A typology of archetypal brand strategies was developed in this paper, referred to here as faces of a company during the pandemic. These faces were based on brand engagement and how COVID-19 science, care and prevention were communicated, and identified here as entertainers, influencers, health informants, active good citizens, science/media watchdogs and human-to-posthumans. Steak-umm was the only company under study that displayed all six faces while, brands such as Dettol, Lysol and Clorox - a bleach manufacturer - demonstrated four. It can be concluded from our earlier analysis of engagement online that humour worked better for Quaker Maid Meats, but this company was not in a strategic marketing position to prevent COVID-19 as was the case for Reckitt Benckiser. There are inferences here also for the potential of building stronger, ethical, socially-robust brands with trust and loyalty. Although beyond science communication, this may be a useful typology for categorising any set of companies that display different public faces in crises or changing market situations, we cannot say, nor does it matter here, the impact that these marketing and engagement strategies have on sales. The broader picture is the taking stock of corporations' involvement in crisis communication while such communication is needed in health sciences, climate sciences and whole areas of science and technology in a new era of globally disruptive events requiring multiple compliances. Scientific institutions in a post-corona, climate-resilient world need to lead with more authority and creditability but also with inclusivity. Ironic methods use a deeper affect and is the currency of social media, used carefully with due respect and reference to the marginalised. The low credibility of Twitter content [Shao et al., 2018] and continuing questions about the suitability of social media for accurate health advice [Moorhead et al., 2013] need to be further addressed. Online voices can sometimes be disparate voices and the words and images used anthropomorphised to the point of being human. While racism and hate speech increase on digital media [Benjamin, 2019; Siapera, Moreo and Zhou, 2018] — and ironic social justice marketing strategies may be deployed to fight this, albeit softly - more inclusivity and trust are even more necessary which require greater flexibility against the perceived hardness of science as an institution, embedding gender and LGBTQI+ 
issues and minority inclusion [Braidotti, 2013]. It is within this type of resistance against false information and social inequalities that we see Steak-umm, Yorkshire Tea, Innocent and others creatively play out this human-to-posthuman identity-shifting in circumstances of toxic Twitter hostility. The ironic anti-marketing marketing of Steak-umm tweeting about the perils of capitalism, Yorkshire Tea telling racists not to drink its tea, or Uber - despite its poor record against workers' rights [Amnesty International UK, 2021] — asking people not to drive their cars and stay at home instead can also be indicative of how brands can recreate and develop the non-material aspect of the brand, and their connotations, while the associated factories might remain closed during lockdown [Hess, 2020]. There are tensions and conflicts, but despite subversions, capitalism remains.

There are implications when corporations step into a vacuum to communicate science in a crisis raising questions of authority and impartiality. At a time when misinformation is increasing, reliable networks are more important than ever. Governments and health organisations were largely successful across the world in getting large-sale compliance on COVID-19 prevention and mitigation measures such as handwashing, wearing face masks and social or physical distancing but signs were showing in 2020-21 of a public backlash and non-compliance. However, state or transnational state agencies have not always succeeded or have been slow to act. It is far from ideal that brands are heroic figures but they have been and may continue to be while this informational form of capitalism exists and while a cross-sectoral set of awareness campaigns requiring urgent action are needed during a global event such as a pandemic and where governments, NGOs, corporations, activists and creatives are called upon to work together, led by organisations tasked with working in the public interest.

Yet there needs to be further investigation into the use of humour, pastiche, even the retro-sci-fi that characterises types of public engagement with science and that challenges corporate communications. It is also not unreasonable to expect, as with corporate social responsibility initiatives, private companies to be used in a coordinated communication effort once there is public awareness of their funding and position. With more freedom from corporate PR, there may even be a place for businesses to utilise irreverent, ironic, anti-marketing critique, embracing - and having fun with - anthropomorphism and posthumanism, while engaging with global challenges like climate change and pandemics.

However, of more importance is the role of the public science communicator in its various guises, including publicly-funded ones - such as education and public engagement officers - or science commentators in high-profile public roles. The increased hybridised, intermediary position of the science, health or environmental communicator means they now have opportunities to play, critique and shape-shift online, and challenge both capitalist idealism and deliberate disinformation - and in the process be posthuman if they need to be, with added humanity.

Acknowledgments I am grateful to Edel Griffiths for assisting with visualisation and the four reviewers whose advice shaped this paper. 
Abitbol, A. (2019). 'Razor burned: why Gillette's campaign against toxic masculinity missed the mark'. The Conversation.

URL: https://theconversation.com/razor-burned-why-gillettes-campaign -against-toxic-masculinity-missed-the-mark-109932 (visited on 14th January 2021).

Altheide, D. L. (1996). Qualitative media analysis. London, U.K.: SAGE Publications. https://doi.org/10.4135/9781412985536.

Amnesty International UK (2021). 'Uber drivers win six year battle over workers' rights in groundbreaking ruling'. Press Releases.

URL: https://www . amnesty . org.uk/press-releases/uk-uber-drivers-win-s ix-year-battle-over-workers-rights-groundbreaking-ruling (visited on 16th March 2021).

Andrews, T. M. (2020). 'Meet the minds behind the bizarre, truth-bombing Steak-umm Twitter account'. The Washington Post. URL: https://www . washingt onpost. com/technology/2020/04/21/steak-umm-twitter-account-feed/ (visited on 14th January 2021).

Applebaum, A. (2020). 'The rest of the world is laughing at Trump'. The Atlantic. URL: https://www. theatlantic.com/ideas/archive/2020/05/time-american s-are-doing-nothing/611056/ (visited on 14th January 2021).

Arvidsson, A. (2006). Brands: meaning and value in media culture. London, U.K. and New York, NY, U.S.A.: Routledge.

Arvidsson, A. and Colleoni, E. (2012). 'Value in informational capitalism and on the Internet'. The Information Society 28 (3), pp. 135-150. https://doi.org/10.1080/01972243.2012.669449.

Ball, J. (2017). Post-truth: how bullshit conquered the world. London, U.K.: Biteback Publishing.

Becker, A. and Anderson, A. A. (2019). 'Using humour to engage the public on climate change: the effect of exposure to one-sided vs. two-sided satire on message discounting, elaboration and counterarguing'. JCOM 18 (04), A07. https://doi.org/10.22323/2.18040207.

Belk, R. W. (1988). 'Possessions and the extended self'. Journal of Consumer Research 15 (2), pp. 139-168. https://doi.org/10.1086/209154.

Benjamin, R. (2019). Race after technology: abolitionist tools for the New Jim Code. Cambridge, U.K.: Polity Press.

Bogomoletc, E. and Lee, N. M. (2021). 'Frozen meat against COVID-19 misinformation: an analysis of Steak-umm and positive expectancy violations'. Journal of Business and Technical Communication 35 (1), pp. 118-125. https://doi.org/10.1177/1050651920959187.

Boltanski, L. and Chiapello, E. (2005). 'The new spirit of capitalism'. International Journal of Politics, Culture, and Society 18 (3-4), pp. 161-188. https://doi.org/10.1007/s10767-006-9006-9.

Braidotti, R. (2013). The posthuman. Cambridge, U.K.: Polity Press.

Brewer, P. R. and McKnight, J. (2015). 'Climate as comedy: the effects of satirical television news on climate change perceptions'. Science Communication 37 (5), pp. 635-657. https://doi.org/10.1177/1075547015597911.

Budd, J., Miller, B. S., Manning, E. M., Lampos, V., Zhuang, M., Edelstein, M., Rees, G., Emery, V. C., Stevens, M. M., Keegan, N., Short, M. J., Pillay, D., Manley, E., Cox, I. J., Heymann, D., Johnson, A. M. and McKendry, R. A. (2020). 'Digital technologies in the public-health response to COVID-19'. Nature Medicine 26 (8), pp. 1183-1192. https : //doi .org/10.1038/s41591-020-1011-4. 
Campbell, N., Deane, C. and Murphy, P. (2015). 'Advertising nanotechnology: imagining the invisible'. Science, Technology, E Human Values 40 (6), pp. 965-997. https://doi.org/10.1177/0162243915574867.

Campbell, N., O'Driscoll, A. and Saren, M. (2010). 'The posthuman: the end and the beginning of the human'. Journal of Consumer Behaviour 9 (2), pp. 86-101. https://doi.org/10.1002/cb.306.

Chadwick, A. (2017). The hybrid media system: politics and power. 2nd ed. Oxford, U.K.: Oxford University Press.

Chakravorty, M. (2020). 'Science fiction explores the interconnectedness revealed by the coronavirus pandemic'. The Conversation.

URL: https://theconversation.com/science-fiction-explores-the-interc onnectedness-revealed-by-the-coronavirus-pandemic-139021.

Chen, Z. F. and Cheng, Y. (2020). 'Consumer response to fake news about brands on social media: the effects of self-efficacy, media trust, and persuasion knowledge on brand trust'. Journal of Product \& Brand Management 29 (2), pp. 188-198. https://doi .org/10.1108/JPBM-12-2018-2145.

Cobb, J. (2018). 'Starbucks and the issue of white space'. The New Yorker. URL: https://www. newyorker.com/magazine/2018/06/04/starbucks-and-the - issue- of -white-space (visited on 17th March 2021).

Colglazier, E. W. (2020). 'Response to the COVID-19 pandemic: catastrophic failures of the science-policy interface'. Science E Diplomacy: an Online Publication from the AAAS Center for Science Diplomacy.

URL: https://www.sciencediplomacy.org/editorial/2020/response-covid19-pandemic-catastrophic-failures-science-policy-interface (visited on 14th January 2021).

Collin, J., Ralston, R., Hill, S. and Westerman, L. (2020). Signalling virtue, promoting harm: unhealthy commodity industries and COVID-19. NCD Alliance, SPECTRUM. URL: https://ncdalliance.org/resources/signalling-virtue-promoting-h arm.

Collins, K., Shiffman, D. and Rock, J. (2016). 'How are scientists using social media in the workplace?' PLoS ONE 11 (10), e0162680. https://doi.org/10.1371/journal . pone.0162680.

Connolly, C. (2020). 'War and the Coronavirus Pandemic'. TWAILR: Reflections \#15. URL: https://twailr.com/war-and-the-coronavirus-pandemic/ (visited on 15th September 2020).

Couldry, N. (2012). Media, society, world: social theory and digital media practice. Cambridge, U.K. and Malden, MA, U.S.A.: Polity Press.

Couldry, N. and Hepp, A. (2017). The mediated construction of reality. Cambridge, U.K. and Malden, MA, U.S.A.: Polity Press.

Crilly, D., Zollo, M. and Hansen, M. T. (2012). 'Faking it or muddling through? Understanding decoupling in response to stakeholder pressures'. Academy of Management Journal 55 (6), pp. 1429-1448. https://doi.org/10.5465/amj.2010.0697.

Dalrymple, K. E., Young, R. and Tully, M. (2016). "“Facts, not fear": negotiating uncertainty on social media during the 2014 Ebola crisis'. Science Communication 38 (4), pp. 442-467. https://doi .org/10.1177/1075547016655546.

Davies, S. R. and Horst, M. (2016). Science communication: culture, identity and citizenship. London, U.K.: Palgrave Macmillan. https://doi.org/10.1057/978-1-137-50366-4.

Davis, E. (1998). Techgnosis: myth, magic, and mysticism in the age of information. Berkeley, CA, U.S.A.: North Atlantic Books. 
Department of Global Communications (2020). 'UN tackles 'infodemic' of misinformation and cybercrime in COVID-19 crisis'. United Nations. URL: https ://www . un.org/en/un-coronavirus-communications-team/un-tackling-\%E2 $\% 80 \% 98$ infodemic $\%$ E2\%80\%99-misinformation-and-cybercrime-covid- 19 (visited on 14th January 2021).

Dubbink, W. and van Liedekerke, L. (2020). 'Rethinking the purity of moral motives in business: Kant against moral purism'. Journal of Business Ethics 167 (3), pp. 379-393. https://doi.org/10.1007/s10551-019-04167-y.

Dylan-Ennis, P. (2021). 'NFT art: the bizarre world where burning a Banksy can make it more valuable'. The Conversation.

URL: https://theconversation.com/nft-art-the-bizarre-world-where-bur ning-a-banksy-can-make-it-more-valuable- 156605 (visited on 18th March 2021).

Edelman, R. (2020). 'Trust Barometer special report: brand trust and the coronavirus pandemic'. Edelman.

URL: https : //www. edelman.com/research/covid-19-brand-trust-report (visited on 13th January 2021).

Epley, N., Waytz, A. and Cacioppo, J. T. (2007). 'On seeing human: a three-factor theory of anthropomorphism'. Psychological Review 114 (4), pp. 864-886. https://doi.org/10.1037/0033-295x.114.4.864.

Evans, W. D., Blitstein, J., Hersey, J. C., Renaud, J. and Yaroch, A. L. (2008). 'Systematic review of public health branding'. Journal of Health Communication 13 (8), pp. 721-741. https://doi.org/10.1080/10810730802487364.

Fahy, D. and Nisbet, M. C. (2011). 'The science journalist online: shifting roles and emerging practices'. Journalism 12 (7), pp. 778-793. https://doi.org/10.1177/1464884911412697.

Felt, U. (2020). 'Public health communication'. In: Exploring science communication: a science and technology studies approach. Ed. by U. Felt and S. R. Davies. London, U.K.: SAGE Publications, pp. 131-148.

Fontaine, G., Lavallée, A., Maheu-Cadotte, M.-A., Bouix-Picasso, J. and Bourbonnais, A. (2018). 'Health science communication strategies used by researchers with the public in the digital and social media ecosystem: a systematic scoping review protocol'. BMJ Open 8 (1), e019833. https://doi.org/10.1136/bmjopen-2017-019833.

Fournier, S. (1998). 'Consumers and their brands: developing relationship theory in consumer research'. Journal of Consumer Research 24 (4), pp. 343-373. https://doi.org/10.1086/209515.

Gatti, L., Seele, P. and Rademacher, L. (2019). 'Grey zone in — greenwash out. A review of greenwashing research and implications for the voluntary-mandatory transition of CSR'. International Journal of Corporate Social Responsibility 4, 6. https://doi .org/10.1186/s40991-019-0044-9.

Gibson, W. (1996). Idoru. New York, NY, U.S.A.: Berkley.

Giesler, M. and Venkatesh, A. (2005). 'Reframing the embodied consumer as cyborg: a posthumanist epistemology of consumption'. In: Advances in Consumer Research. Ed. by G. Menon and A. R. Rao. Vol. 32. Duluth, MN, U.S.A.: Association for Consumer Research, pp. 661-669.

Greenpeace (2006). Green My Apple Projection San Francisco.

URL: https://www . greenpeace org/usa/apple-can-be-an-environmental-le ader-again/green-my-apple-projection-san-francisco/ (visited on 14th January 2021). 
Hess, A. (2020). 'The pandemic ad salutes you'. The New York Times. URL: https://w ww. nytimes . com/2020/05/22/arts/pandemic-ads-salute-you.html (visited on 14th January 2021).

Hill, A. (2019). 'The hidden power of corporate virtue signals'. Financial Times. URL: https://www.ft.com/content/5f2142c4-f5a6-11e9-9ef3-eca8fc8f2d65 (visited on 14th January 2021).

Holliman, R., Whitelegg, E., Scanlon, E., Smidt, S. and Thomas, J., eds. (2009). Investigating science communication in the information age: implications for public engagement and popular media. Oxford, U.K.: Oxford University Press.

Horowitz, D. (2012). Consuming pleasures: intellectuals and popular culture in the postwar world. Philadelphia, PA, U.S.A.: University of Pennsylvania Press. https://doi.org/10.9783/9780812206494.

Houck, B. (2018). 'Steak-umm exploits millennial angst to sell frozen cheesesteak filling'. Eater. URL: https://www . eater . com/2018/9/27/17907508/steak-ummtwitter-exploits-millennial-angst-to-sell-sliced-steak (visited on 14th January 2021).

Jahdi, K. S. and Acikdilli, G. (2009). 'Marketing communications and corporate social responsibility (CSR): marriage of convenience or shotgun wedding?' Journal of Business Ethics 88 (1), pp. 103-113. https://doi.org/10.1007/s10551-009-0113-1.

Jansen, B. J., Zhang, M., Sobel, K. and Chowdury, A. (2009). 'Twitter power: tweets as electronic word of mouth'. Journal of the American Society for Information Science and Technology 60 (11), pp. 2169-2188. https://doi.org/10.1002/asi.21149.

Joubert, M. and Wasserman, H. (2020). 'Spikey blobs with evil grins: understanding portrayals of the coronavirus in South African newspaper cartoons in relation to the public communication of science'. JCOM 19 (07), A08. https://doi.org/10.22323/2.19070208.

Kalpokas, I. (2019). 'Affective encounters of the algorithmic kind: post-truth and posthuman pleasure'. Social Media + Society 5 (2). https://doi.org/10.1177/2056305119845678.

Kantar (2020). COVID-19 Barometer.

URL: https : / www . kantar . com/campaigns/covid-19-barometer (visited on 14th January 2021).

Kiefer, B. (2020). 'Ice-cream, activism and puns: how Ben \& Jerry's models purpose in an age of outrage'. Campaign.

URL: https://www . campaignlive.co.uk/article/ice-cream-activism-punsben-jerrys-models-purpose-age-outrage/1694663 (visited on 17th March 2021).

Kozinets, R. V. (2008). 'Technology/ideology: how ideological fields influence consumers' technology narratives'. Journal of Consumer Research 34 (6), pp. 865-881. https://doi.org/10.1086/523289.

- (2015). 'The post-human future of brands'. In: Strong brands, strong relationships. Ed. by S. Fournier, M. J. Breazeale and J. Avery. London, U.K.: Routledge, pp. 149-160.

Krause, N. M., Freiling, I., Beets, B. and Brossard, D. (2020). 'Fact-checking as risk communication: the multi-layered risk of misinformation in times of COVID-19'. Journal of Risk Research 23 (7-8), pp. 1052-1059. https://doi.org/10.1080/13669877.2020.1756385.

Kuipers, G. (2016). 'Follow the joke: humour and ethnography'. Etnofoor 28 (2), pp. 125-129. URL: https://www. jstor.org/stable/44013450. 
Law, J. (2008). ‘On sociology and STS'. The Sociological Review 56 (4), pp. 623-649. https://doi.org/10.1111/j.1467-954x.2008.00808.x.

Lazzarato, M. (1997). Lavoro immateriale. Verona, Italy: Ombre Corte.

Lee, N. M. and VanDyke, M. S. (2015). 'Set it and forget it: the one-way use of social media by government agencies communicating science'. Science Communication 37 (4), pp. 533-541. https://doi.org/10.1177/1075547015588600.

Levinson, P. (2017). Fake news in real context. U.K.: Connected Editions.

Logan, N. (2016). 'The Starbucks Race Together initiative: analyzing a public relations campaign with critical race theory'. Public Relations Inquiry 5 (1), pp. 93-113. https://doi.org/10.1177/2046147x15626969.

MacInnis, D. J. and Folkes, V. S. (2017). 'Humanizing brands: when brands seem to be like me, part of me, and in a relationship with me'. Journal of Consumer Psychology 27 (3), pp. 355-374. https://doi.org/10.1016/j.jcps.2016.12.003.

Michael, M. (1996). Constructing identities: the social, the nonhuman and change. London, U.K.: SAGE Publications. https ://doi .org/10 .4135/9781446279182.

Mol, A. (2003). The body multiple: ontology in medical practice. Durham, NC, U.S.A.: Duke University Press.

Moorhead, S. A., Hazlett, D. E., Harrison, L., Carroll, J. K., Irwin, A. and Hoving, C. (2013). 'A new dimension of health care: systematic review of the uses, benefits and limitations of social media for health communication'. Journal of Medical Internet Research 15 (4), e85. https://doi.org/10.2196/jmir. 1933.

Nabi, J. (2018). 'How coffee shop racism harms black patients'. MedicalXpress. URL: https://medicalxpress.com/news/2018-05-coffee-racism-black-pati ents . html (visited on 10th March 2021).

Newell, J. L. (2020). 'Italian politics in 2019 and their legacy: reactions to the coronavirus'. Contemporary Italian Politics 12 (2), pp. 109-111. https://doi.org/10.1080/23248823.2020.1753315.

Nilson, I. and Wikberg, E., eds. (2021). Artful objects: Graham Harman on art and the business of speculative realism. Berlin, Germany: Sternberg Press.

Ofcom (2020). Covid-19 news and information: summary of views about misinformation. URL: https://www. of com.org.uk/__data/assets/pdf_file/0029/197732/cov id-19-news-consumption-week-fourteen-misinformation-summary . pdf (visited on 14th January 2021).

Peters, M. A. and Jandrić, P. (2019). 'Posthumanism, open ontologies and bio-digital becoming: response to Luciano Floridi's Onlife Manifesto'. Educational Philosophy and Theory 51 (10), pp. 971-980. https://doi.org/10.1080/00131857.2018.1551835.

Reckitt Benckiser (2020). Improper use of disinfectants. URL: https : //www .rb . com/med $\mathrm{ia/news/2020/april/improper-use-of-disinfectants/(visited} \mathrm{on}$ 14th January 2021).

Riesch, H. (2015). 'Why did the proton cross the road? Humour and science communication'. Public Understanding of Science 24 (7), pp. 768-775. https://doi.org/10.1177/0963662514546299.

Roth, S., Valentinov, V., Heidingsfelder, M. and Pérez-Valls, M. (2020). 'CSR beyond economy and society: a post-capitalist approach'. Journal of Business Ethics 165 (3), pp. 411-423. https://doi.org/10.1007/s10551-018-4068-y.

Rumbo, J. D. (2002). 'Consumer resistance in a world of advertising clutter: the case of Adbusters'. Psychology \& Marketing 19 (2), pp. 127-148.

https://doi.org/10.1002/mar.10006. 
Sanders, J. and van Krieken, K. (2018). 'Exploring narrative structure and hero enactment in brand stories'. Frontiers in Psychology 9, 1645.

https://doi.org/10.3389/fpsyg.2018.01645.

Scheufele, D. A. and Krause, N. M. (2019). 'Science audiences, misinformation, and fake news'. Proceedings of the National Academy of Sciences 116 (16), pp. 7662-7669. https://doi.org/10.1073/pnas.1805871115.

Scheufele, D. A., Krause, N. M., Freiling, I. and Brossard, D. (2020). 'How not to lose the COVID-19 communication war'. Issues in Science and Technology. URL: https://issues .org/covid-19-communication-war/ (visited on 14th January 2021).

Shao, C., Ciampaglia, G. L., Varol, O., Yang, K.-C., Flammini, A. and Menczer, F. (2018). 'The spread of low-credibility content by social bots'. Nature Communications 9, 4787. https://doi .org/10.1038/s41467-018-06930-7.

Siapera, E. (2011). Understanding new media. London, U.K.: SAGE Publications.

Siapera, E., Moreo, E. and Zhou, J. (2018). Hate Track: tracking and monitoring racist speech online. Irish Research Council.

URL: https://www.ihrec.ie/app/uploads/2018/11/HateTrack-Tracking-and -Monitoring-Racist-Hate-Speech-Online.pdf (visited on 14th January 2021).

Solnit, R. (2019). 'When the hero is the problem: on Robert Mueller, Greta Thunberg, and finding strength in numbers'. LitHub.

URL: https://lithub.com/rebecca-solnit-when-the-hero-is-the-problem/ (visited on 14th January 2021).

Stilgoe, J., Lock, S. J. and Wilsdon, J. (2014). ‘Why should we promote public engagement with science?' Public Understanding of Science 23 (1), pp. 4-15. https://doi.org/10.1177/0963662513518154.

Thomas, Z. (2020). 'Coronavirus: will COVID-19 speed up the use of robots to replace human workers?' $B B C$ News.

URL: https://www. bbc. com/news/technology-52340651 (visited on 14th January 2021).

Thomson, M. (2006). 'Human brands: investigating antecedents to consumers' strong attachments to celebrities'. Journal of Marketing 70 (3), pp. 104-119. https://doi.org/10.1509/jmkg.70.3.104.

Thrift, N. (2004). 'Intensities of feeling: towards a spatial politics of affect'. Geografiska Annaler: Series B, Human Geography 86 (1), pp. 57-78. https://doi.org/10.1111/j.0435-3684.2004.00154.x.

- (2005). Knowing capitalism. London, U.K.: SAGE Publications. https://doi.org/10.4135/9781446211458.

- (2011). 'Lifeworld Inc - and what to do about it'. Environment and Planning D: Society and Space 29 (1), pp. 5-26. https://doi .org/10.1068/d0310.

- (2014). 'The 'sentient' city and what it may portend'. Big Data \& Society 1 (1). https://doi.org/10.1177/2053951714532241.

Turner Schenk, C. and Holman, R. H. (1980). 'A sociological approach to brand choice: the concept of situational self image'. In: Advances in Consumer Research. Ed. by J. C. Olson. Vol. 7. Ann Abor, MI, U.S.A.: Association for Consumer Research, pp. 610-614.

van Dijck, J. and Poell, T. (2013). 'Understanding social media logic'. Media and Communication 1 (1), pp. 2-14. https://doi.org/10.17645/mac.v1i1.70.

Warren, C. and Mohr, G. S. (2017). 'Ironic consumption'. In: Advances in Consumer Research. Ed. by A. Gneezy, V. Griskevicius and P. Williams. Vol. 45. Duluth, MN, U.S.A.: Association for Consumer Research, pp. 952-954. 
Weingart, P. and Joubert, M. (2019). 'The conflation of motives of science communication - causes, consequences, remedies'. JCOM 18 (03), Y01. https://doi.org/10.22323/2.18030401.

WHO (2021). 'Let's flatten the infodemic curve'. World Health Organization. URL: https://www. who. int/news-room/spotlight/let-s-flatten-the-infod emic-curve (visited on 13th January 2021).

Woolley, S. C. and Howard, P. N. (2016). 'Social media, revolution, and the rise of the political bot'. In: Routledge handbook of media, conflict, and security. Ed. by P. Robinson, P. Seib and R. Fröhlich. London, U.K.: Routledge, pp. 282-292. https://doi .org/10.4324/9781315850979-33.

Wynne, B. (1992). 'Misunderstood misunderstanding: social identities and public uptake of science'. Public Understanding of Science 1 (3), pp. 281-304. https://doi.org/10.1088/0963-6625/1/3/004.

Author

\section{How to cite}

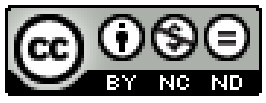

Dr. Pádraig Murphy is Assistant Professor in Communication at Dublin City University and Chair of the MSc in Science and Health Communication programme. His teaching and research interests include science communication, Science and Technology Studies and public engagement with science and technology. His research and writing focuses on deliberative and participatory dialogue models for biotechnology, nanotechnology, green innovation and other future and emerging technologies. Dr. Murphy is the Irish Principal Investigator on several European Horizon 2020 engaged research projects on Responsible Research and Innovation.

Dr. Murphy also coordinates the Celsius research group at DCU. He was appointed to the Campus Engage working group on Engaged Research in 2015. He is author of 'Biotechnology, Education and Life Politics: Debating Genetic Futures from School to Society' (Routledge, 2014) and co-author of 'Little Country, Big Talk: Science Communication in Ireland' (2017). E-mail: padraig.murphy@dcu.ie.

Murphy, P. (2021). 'Steak and bleach as science communication heroes? The rise of post-corona, posthuman irony'. JCOM 20 (05), A03. https://doi.org/10.22323/2.20050203. 